\title{
iassist NEWSLETTER vol.1, no.1
}

Some of the respondents to the membership campaign letter recommended the creation of other Action Groups, such as the hardware/software technology Action Group (Data Organization and Management) and a cross-file indexing Action Group. other suggestions included a group to interface between information data bases and potential users and a group to examine the relationship between bibliographic data bases, statistical data bases, and IASSIST.

Initial response to the IASSIST mailing indicates that there is considerable enthusiasm for such an organization in Canada. It will be up to the Canadian members of IASSIST to decide whether their needs can best be served by merging with the US organization in a North American IASSIST movement or by working closely with the Americans in matters of common interest, but continuing to maintain a separate Secretariat and a separate voice at the international level.

\section{West European Secretariat Report}

\author{
Per Nielsen \\ Danish Data Archives
}

In Europe, the IASSIST membership campaign in September, 1975, resulted in an immediate response from more than 80 interested individuals -- and names are continuously comin' in. In the Spring of 1976, a number of European social science data archives agreed to provide information dissemination facilities for IASSIST. Consequently, all individuals having indicated an interest in IASSIST will receive mailings according to the following geographical division, where bracketed numbers indicate the approximate "membership" size in May, 1976:

Greece, Italy, and Spain: Archivio dati e programmi per le scienze socialj (ADPSS), Milan (7); Belgium, France, and French-speaking Switzerland: Belgian Archives for the Social Sciences (BASS), Louvain-la-Neuve (8); Denmark: Danish Data Archives (DDA), Copenhagen (7); Eire, Israel, and the United Kingdom: SSRC Survey Archive, Essex (21); Finland, Norway, and Sweden: Norwegian Social Science Data Services (NSD), Bergen (13); the Netherlands: Steinmetzarchief, Amsterdam (7); Austria, the Federal Republic of Germany, and German-speaking Switzerland: Zentralarchiv (ZA), Cologne (14). Until recentiy, the $Z A$ has also disseminated information to half a dozen potential members in Eastern Europe; these people (and, we hope a lot more to be brought in) will now be served by Dr. Ostrowski of the Polish Academy of Sciences, Warsaw.

Prior to the Edinburgh meetings an overall mailing was carried out, including information on the Action Groups in Europe. Within a few months, we hope that the Action Groups have defined the priority of tasks so that workshops and other substantive activities accomplishing the objectives of IASSIST can be scheduled for 1977. 